\title{
Use of GIS to Determine Potential Sources of Aquatic Invasive Species Invasions into Western South Dakota Reservoirs
}

\author{
Jayne Kylee Ecker, Ryan Raben, Greg Simpson* \\ South Dakota Department of Game, Fish and Parks, Rapid City, SD, USA \\ Email: *greg.simpson@state.sd.us
}

How to cite this paper: Ecker, J.K., Raben, R. and Simpson, G. (2020) Use of GIS to Determine Potential Sources of Aquatic Invasive Species Invasions into Western South Dakota Reservoirs. Natural Resources, 11, 39-45.

https://doi.org/10.4236/nr.2020.112003

Received: January 3, 2020

Accepted: February 22, 2020

Published: February 25, 2020

Copyright $\odot 2020$ by author(s) and Scientific Research Publishing Inc. This work is licensed under the Creative Commons Attribution International License (CC BY 4.0).

http://creativecommons.org/licenses/by/4.0/

\begin{abstract}
The spread of Aquatic Invasive Species (AIS) is a constant threat for western US waters. The state of South Dakota detected zebra mussels (Dreissena polymorpha) for the first time at Lewis and Clark Reservoir in 2014. Since then, efforts have been towards preventing their further expansion. To determine possible avenues of infestation westward, we used ArcGIS to map the home zip codes of boaters using four western reservoirs (Belle Fourche Reservoir, Pactola Reservoir, Sheridan Lake and Angostura Reservoir). A 60-mile buffer was used to determine spatial relationships of boater zip codes to establish zebra mussel populations and was considered areas of high risk. We found that there were three instances where a boater came from a high-risk area during the study period. Our results show possible pathways for Dreissena expansion into western South Dakota reservoirs. Most notably is that exposure can occur from either an inter- or intra-state vector. This information confirmed that there is a risk of additional water bodies in South Dakota becoming infected. Based on past studies, prevention is the best method in slowing the expansion of zebra mussels in South Dakota. We suggest three actions, strategically placed decontamination stations, continued public awareness efforts and differentiating boat registration tags on watercraft that are near infested water bodies.
\end{abstract}

\section{Keywords}

GIS, South Dakota, Invasive Species, Zebra Mussel

\section{Introduction}

Most scientists agree that released contaminated ballast water into the Great Lakes from a cargo ship was the initiation of Dreissena mussels into North 
America. Since that time, the expansion of Dreissena mussels (zebra mussels Dreissena polymorpha and quagga mussels Dreissena rostriformis bugensis) has been a major issue in the United States [1] [2] [3]. Lacking natural controls, these mussels have thrived in this new environment while spreading throughout water bodies connected to the Great Lakes and secondarily spreading through carriers of Dreissena mussels [2] [4] and [5]. Zoological spreading of these mussels occurs through different life-history stages.

These two Dreissena mussels have similar life history characteristics including high reproductive potential, planktonic free-swimming larvae [6], and an attached benthic adult stage [1]. Range expansion occurs in these two life stages, during the free-floating veliger larval stage and in attached adult stage [3]. During the larval stage contaminated water is a potential source of infestation. As adults, Dreissena mussels can be spread by attaching themselves to a transferrable object (e.g. rock, boat hull, trailer) by its byssal threads [7]. Spatial analysis has allowed researchers to visualize the spread of Dreissena mussels across the United States.

Geographic Information System (GIS) has been used to track Dreissena mussels [8] and to predict infestation by mapping major access points [9], and predict areas of potential colonization [9] [10] [11] and [12], and zebra mussel's development/reproduction success rates per lake [13]. The use of GIS mapping has reinforced past theories that zebra mussels can move through connected waterways but also by other methods of dispersal (i.e. recreational boaters) [4] [14] and [15]. As a tool, GIS allows for various analysis that would be difficult otherwise (e.g. buffer analysis). Our objective was to determine the potential pathways of Dreissena mussel introductions into western South Dakota reservoirs using GIS and to provide direction towards limiting or delaying these infestations.

\section{Methods}

Four popular recreational lakes (Belle Fourche Reservoir, Angostura Reservoir, Pactola Reservoir and Sheridan Lake) in western South Dakota were sampled between May 19 and July 15, 2018 and were selected based on high boating use and multiple launching sites (Figure 1). Boaters were interviewed, normally before launching, a series of questions used later in analysis.

We used three data layers and two processes within ArcGIS to perform our analysis of greatest potential Dreissena pathways to western South Dakota reservoirs (Figure 2). First, we combined 5-digit zip code data from boater interviews to data from the Esri Digital Line graph data for the USA to provide a geographic location to user zip codes. The centroid of each zip code polygon was used as a standard location in which to determine proximity of other factors. Zebra and quagga infestation sites were imported from US Geological Service Nonindigenous Aquatic Species and were spatially associated to the nearest zip code [16]. Next, a buffer analysis was processed in ArcGIS based on a 60-mile unit. This distance was used based on the assumption that most boating activity 
would be within an hour of a person's normal residence (i.e. zip code) and resembled distances found by [17]. Based on this estimation, a 60-mile radius buffer zone was placed around each zip code point. Lastly, all the Dreissena infested water bodies that were not inside the buffer zones were eliminated from the map leaving only high-risk zip code areas.

\section{Results}

Throughout the study, 107 boater surveys were taken between the four lakes which yielded 26 unique user zip codes. Boaters to these four waters were from six different states (Figure 3). Additionally, zip codes were used to show spatial orientation to Dreissena infested waterbodies. Seven zip codes were not within South Dakota, coming from five different states (North Dakota, Wyoming, Colorado, Iowa and Arkansas), with three of these states (South Dakota, Colorado and Arkansas) having Dreissena infested waters. By using a 60-mile buffer to the center of the boater zip codes we determined that three of the zip codes are in high risk areas with Dreissena mussel infested water bodies in easy driving distance and could be considered high-risk for potentially spreading Dreissena mussels into western South Dakota.

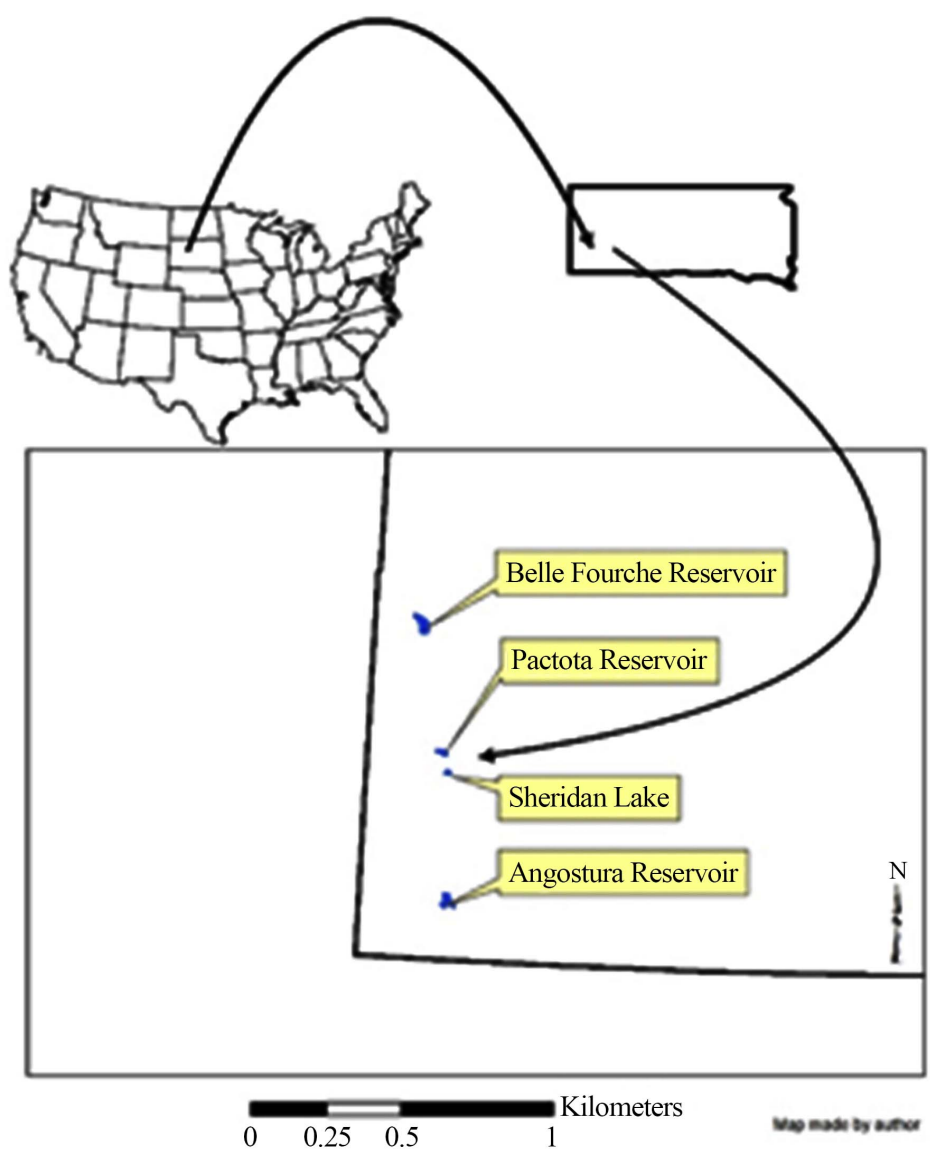

Figure 1. Study area of western South Dakota and four specified waters used in data collection. Figure made by author. 


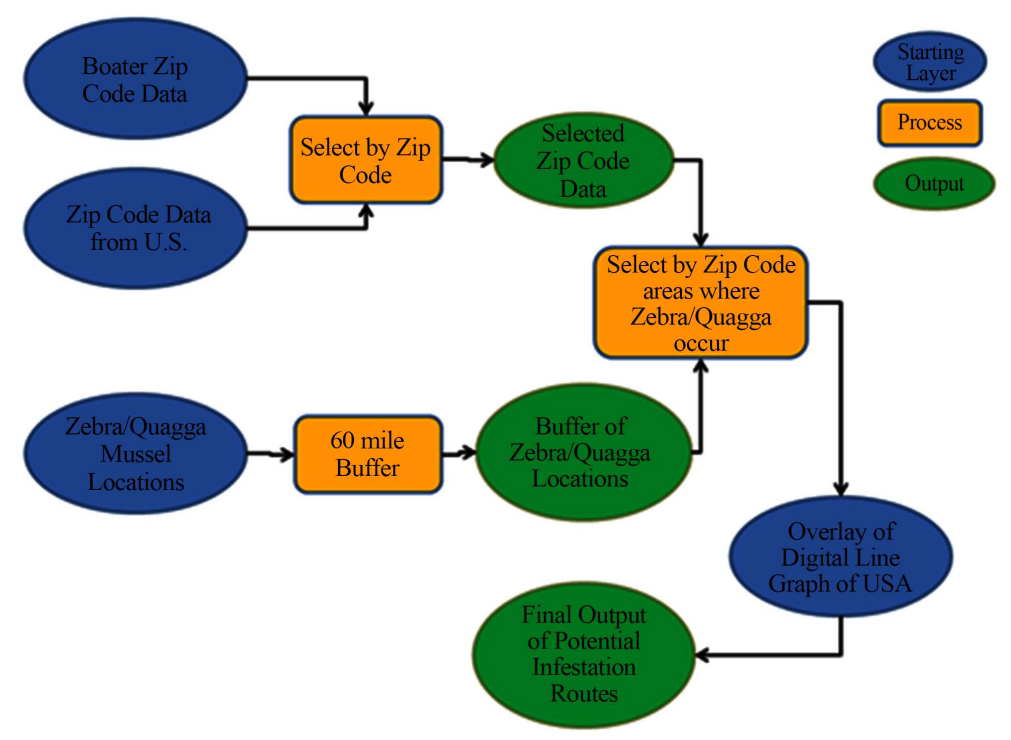

Figure 2. Model schematic of layers, processes and final output for determining potential sources of Zebra and Quagga mussel spread into western South Dakota. Figure made by author.

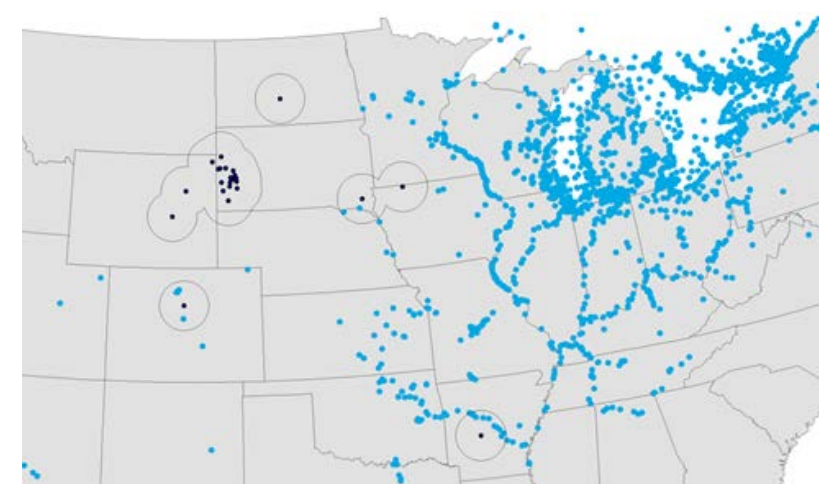

Figure 3. Geographical locations of 60-mile buffered areas around zip codes where zebra mussels were within the specified distance (black dots with buffered areas) and total area in the central US where Zebra and Quagga mussels are located (blue dots). Figure made by author.

\section{Discussion}

Expansion of the invasion of Dreissena mussels across the United States has been relatively unsuppressed. Continued efforts to address the extension of infected waters are hampered by water movement of infested water or possibly even attached adults themselves. This means that any boat carrying water containing veligers, or that has adult mussels attached to any part of the boat or trailer, could initiate the establishment of Dreissena mussels in any new waters.

Zebra mussels were first discovered in South Dakota at Lewis and Clark Reservoir in 2014 [17]. Since 2014, multiple water bodies in the eastern side of South Dakota have been noted as being contaminated with Dreissena mussels [18]. In order to delay or stop the spread of Dreissena mussels in South Dakota, certain actions should be taken. One such action is disinfection stations or com- 
pletely closing access points to affected reservoirs until a disinfection station can be put in place. These disinfection stations would allow either officials or boaters to disinfect their boat upon arrival to an uninfected lake or before leaving an infested one [18]. Public awareness is also an effective way to prevent the spread of mussels. The simple act of informing the public about the issues that these mussels cause, how to identify if their equipment as possible infection points can reduce the chance of dispersal caused by lack of knowledge [18]. Also, an educated public can be used as a tool to identify early detection of invasive species spread [19]. Another prevention method is to specially mark registration stickers on boats coming from areas infested with Dreissena mussels. Having differentiated registration stickers would allow law enforcement to easily identify high risk boats and inspect them before they are launched [18].

From our analysis, there are three areas of concern that might be a source of Dreissena infestation into wester South Dakota lakes (Figure 3). Two are these areas are out-of-state (Colorado and Arkansas) with one lone presence coming from the southeastern part of South Dakota. This indicates that to reduce the presence in western South Dakota waters, at least a bimodal approach including boat inspections within state and incoming will be required. This information could also allow for the targeting of specific educational awareness efforts directed at boaters to reduce chances of Dreissena expansion. Additional efforts directed towards determining if waters are suitable for expansion [20] and to determine early detection of invasive species [21] [22] [23].

Since a single contaminated boat can infect a water body, without prevention measures in place, there is an imminent threat of our waters becoming infected. Using the Great Lakes as the initial infestation site, scientists were able to trace the spread of Dreissena mussels through connecting water bodies and traveling south in streams using the ArcGIS system. Western expansion can be seen throughout the country and elsewhere that can only be attributed to an unnatural movement created by recreational boaters [22] [24] [25]. Based on the infestation map given by the US Geological Service Nonindigenous Aquatic Species it is apparent that there is a greater concentration of Dreissena mussels on the eastern and southern borders of South Dakota [22].

\section{Conclusions}

We suggest that efforts be more focused on boaters coming from the Missouri River and State of South Dakota's southern border. Much of the potential for infestation is likely to come from established populations from these regions. As a tool, GIS can aid in understanding potential infestation pathways and perhaps allow for evidence of need for specific regulations to limit AIS expansion within South Dakota.

Our results show possible pathways for Dreissena expansion into western South Dakota reservoirs (Figure 3). Most notably is that range extension can occur from either an inter- or intra-state vector. Normal efforts are to educate 
and boaters with "spot checks" of vessels entering the waters. Knowing the potential pathways of Dreissena mussels into western South Dakota will allow managers to target educational outreach, boat checks and allocate resources in a fiscally responsible manner. These results of this study would have been difficult to determine without the use of GIS.

\section{Acknowledgements}

We thank McKenzie Hansen and Megan Andersen for their assistance with this study.

\section{Conflicts of Interest}

The authors declare no conflicts of interest regarding the publication of this paper.

\section{References}

[1] Hebert, P.D.N., Muncaster, B.W. and Mackie, G.L. (1989) Ecological and Genetic Studies on Dreissena polymorpha (Pallas): A New Mollusk in the Great Lakes. Canadian Journal of Fisheries and Aquatic Sciences, 46, 1587-1591. https://doi.org/10.1139/f89-202

[2] Roberts, L. (1990) Zebra Mussel Invasion Threatens U.S. Waters. Science, 249, 1370-1372. https://doi.org/10.1126/science.249.4975.1370

[3] McMahon, R.F. (1996) The Physiological Ecology of the Zebra Mussel, Dreissena polymorpha, in North America and Europe. American Zoology, 36, 339-363. https://doi.org/10.1093/icb/36.3.339

[4] Zanden, M.J.V. and Olden, J.D. (2008) A Management Framework for Preventing the Secondary Spread of Aquatic Invasive Species. Canadian Journal of Fisheries and Aquatic Sciences, 65, 1512-1522. https://doi.org/10.1139/F08-099

[5] Benson, A.J., Raikow, D., Larson, J., Fusaro, A. and Bogdanoff, A.K. (2015) Dreissena polymorpha. USGS Nonindigenous Aquatic Species Database, Gainesville. http://nas.er.usgs.gov/queries/FactSheet.aspx?speciesID $=5$

[6] Beletsky, D., Beletsky, R., Rutherford, E.S., Sieracki, J.L., Bossenbroek, J.M., Chadderton, W.L., Wittmann, M.E., Annis, G.M. and Lodge, D.M. (2017) Predicting Spread of Aquatic Invasive Species by Lake Currents. Journal of Great Lakes Research, 43, 14-32. https://doi.org/10.1016/j.jglr.2017.02.001

[7] Sun, C. and Waite, J.H. (2005) Mapping Chemical Gradients within and along a Fibrous Structural Tissue, Mussel Byssal Threads. Journal of Biological Chemistry, 280, 39332-39336. https://doi.org/10.1074/jbc.M508674200

[8] Ashby, S.L., Boyd, W.A. and Kennedy, R.H. (1998) Assessing the Potential for Zebra Mussel Habitat at US Army Corps of Engineers Water Resources Projects Using GIS Techniques and Water Quality Data. Proceedings of the 8 th International Zebra Mussel and Aquatic Nuisance Species Conference, Sacramento, 16-19 March 1998, 300-305.

[9] Koutnik, M.A. and Padilla, D.K. (1994) Predicting the Spatial Distribution of Dreissena polymorpha (Zebra Mussel) among Inland Lakes of Wisconsin: Modeling with a GIS. Canadian Journal of Fisheries and Aquatic Sciences, 51, 1189-1196. https://doi.org/10.1139/f94-118

[10] Ramcharan, C.W., Padilla, D.K. and Dodson, S.I. (1992) Models to Predict Potential Occurrence and Density of the Zebra Mussel, Dreissena polymorpha. Canadian Jour- 
nal of Fisheries and Aquatic Sciences, 49, 2611-2620. https://doi.org/10.1139/f92-289

[11] Haltuch, M.A., Berkman, P.A. and Garton, D.W. (2000) Geographic Information System (GIS) Analysis of Ecosystem Invasion: Exotic Mussels in Lake Erie. Limnology and Oceanography, 45, 1778-1787. https://doi.org/10.4319/lo.2000.45.8.1778

[12] Chakraborti, R.K., Kaur, J. and DePinto, J.V. (2002) Analysis of Factors Affecting Zebra Mussel (Dreissena polymorpha) Growth in Saginaw Bay: A GIS-Based Modeling Approach. Journal of Great Lakes Research, 28, 396-410. https://doi.org/10.1016/S0380-1330(02)70593-5

[13] Martinez, B., Reaser, J.K., Dehgan, A., Zamft, B., Baisch, D., McCormick, C., Giordano, A.J., Aicher, R. and Selbe, S. (2019) Technology Innovation: Advancing Capacities for the Early Detection of and Rapid Response to Invasive Species. Biological Invasions, 22, 75-100. https://doi.org/10.1007/s10530-019-02146-y

[14] Neary, B.P. and Leach, J.H. (1992) Mapping the Potential Spread of the Zebra Mussel (Dreissena polymorpha) in Ontario. Canadian Journal of Fisheries and Aquatic Sciences, 49, 406-415. https://doi.org/10.1139/f92-046

[15] Joshi, C., Leeuw, J. and van Duren, I.C. (2004) Remote Sensing and GIS Applications for Mapping and Spatial Modeling of Invasive Species. Department of Natural Resources, International Institute for Geo-Information Science and Earth Observation (ITC).

https://pdfs.semanticscholar.org/5a80/503a9f916ffabe32aa4b52371f4bc910af00.pdf? ga $=2.148508215 .1249587964 .1545838423-1607248357.1545838423$

[16] U.S. Geological Survey (2018) Non-Indigenous Aquatic Species Database. Gainesville. http://nas.er.usgs.gov

[17] Gates, K.K., Guy, C.S., Zale, A.V. and Horton, T.B. (2009) Angler Awareness of Aquatic Nuisance Species and Potential Transport Mechanisms. Fisheries Management and Ecology, 16, 448-456. https://doi.org/10.1111/j.1365-2400.2009.00694.x

[18] Smith, M. (2015) Don't Move a Mussel. South Dakota Conservation Digest.

[19] Leifer, D. and Wilson, C.O. (2017) Development of a Multi-Platform Volunteered Geographic Information Application for Monitoring Invasive Species of Asian Carp in the Upper Mississippi River System. University of Wisconsin Eau Claire, Eau Claire. http://digital.library.wisc.edu/1793/76270

[20] Barnes, M.A. and Patiño, R. (2020) Predicting Suitable Habitat for Dreissenid Mussel Invasion in Texas Based on Climatic and Lake Physical Characteristics. Management of Biological Invasions, 11.

[21] Morisette, J.T., Reaser, J.K., Cook, G.L., Irvine, K.M. and Roy, H.E. (2019) Right Place. Right Time. Right Tool: Guidance for Using Target Analysis to Increase the Likelihood of Invasive Species Detection. Biological Invasions, 22, 67-74. https://doi.org/10.1007/s10530-019-02145-Z

[22] Zebra Mussels. USGS, Date Modified Oct. 24, 2018. https://nas.er.usgs.gov/viewer/omap.aspx?SpeciesID $=5$

[23] Duran, C., Lanao, M., Anadon, A. and Touya, V. (2010) Management Strategies for the Zebra Mussel Invasion in the Ebro River Basin. Aquatic Invasions, 5, 309-316. https://doi.org/10.3391/ai.2010.5.3.09

[24] Duran, C. and Anadon, A. (2008) The Zebra Mussel Invasion in Spain and Navigation Rules. Aquatic Invasions, 3, 315-324. https://doi.org/10.3391/ai.2008.3.3.6

[25] Goldsmit, J., Archambault, P., Chust, G., Villarino, E., Liu, G. and Lukovich, J. (2018) Projecting Present and Future Habitat Suitability of Ship-Mediated Aquatic Invasive Species in the Canadian Arctic. Biological Invasions, 20, 501-517. https://doi.org/10.1007/s10530-017-1553-7 